\title{
Inadvertently Found Thoracic Ectopic Liver Confirmed without Surgery
}

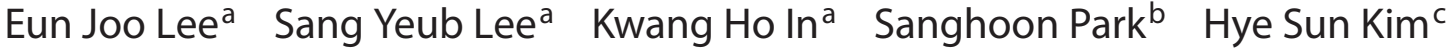 \\ ${ }^{a}$ Division of Respiratory and Critical Care Medicine, Departments of Internal Medicine, Korea University \\ College of Medicine, ${ }^{b}$ Division of Gastroenterology and Hepatology, Department of Internal Medicine, \\ KEPCO Medical Foundation, Hanil General Hospital, and ' ${ }^{\mathrm{C}}$ Department of Pathology, Cheil General Hospital and \\ Women's Healthcare Center, Kwandong University College of Medicine, Seoul, Korea
}

A 65-year-old female who had never smoked presented with an abnormal chest X-ray. She was an osteoporotic patient and had a chest X-ray as a check-up. She denied any respiratory symptoms including cough, sputum, dyspnoea, haemoptysis or pleuritic chest pain. There were no positive findings on physical examination.
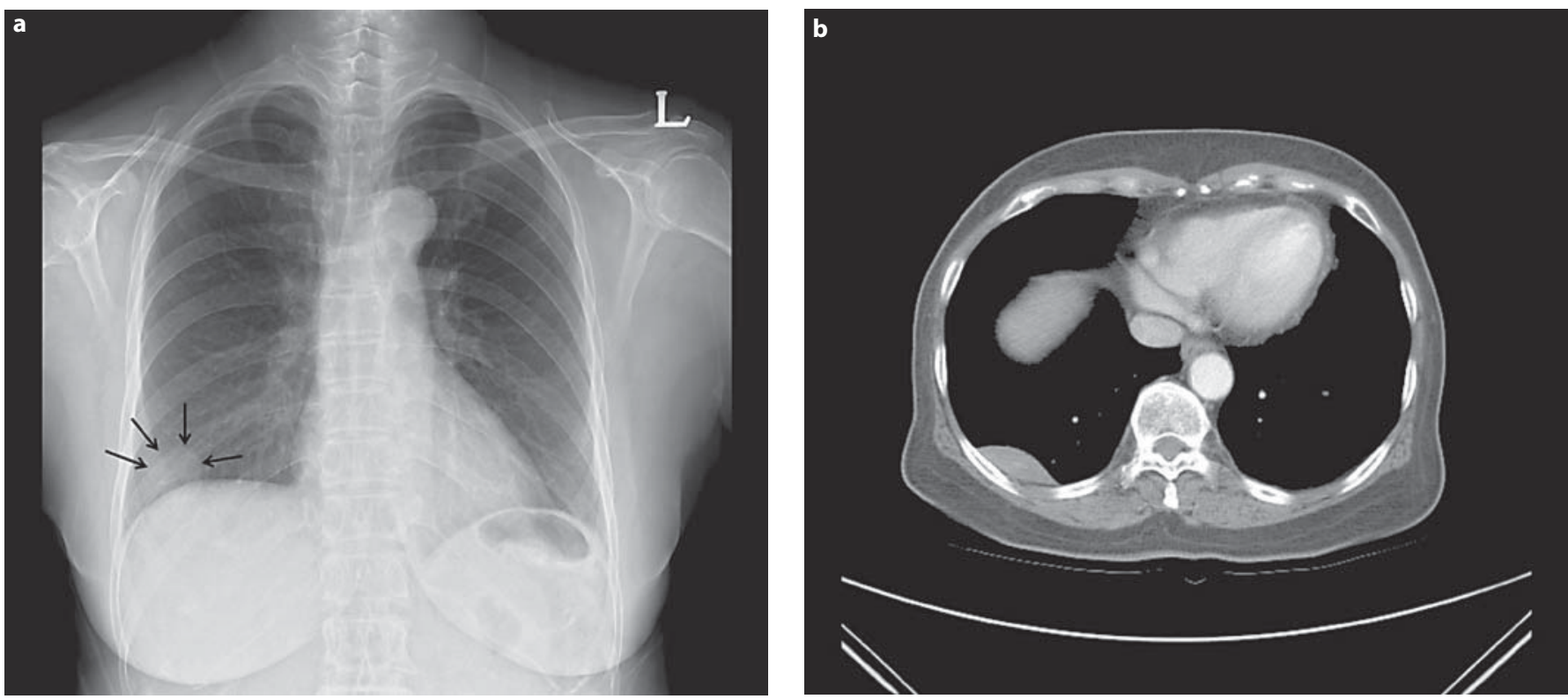

Fig. 1. Chest posterior-anterior radiography (a) and CT (b) showed a smooth, slightly enhanced, pleural softtissue mass close to the right diaphragm.

\section{KARGER}

Fax +41 613061234 E-Mail karger@karger.ch www.karger.com
C) 2010 S. Karger AG, Basel

0025-7931/11/0814-0343\$38.00/0

Accessible online at:

www.karger.com/res
Chest X-ray (fig. 1a, arrows) and a contrast-enhanced CT scan (fig. 1b) demonstrated a well-defined, homogeneous, pleural soft-tissue mass close to the right diaphragm. It was slightly enhanced, similar to that of a normal liver without any anatomic connection with subpleural, normal liver. A diagnostic CT-guided transthoracic 

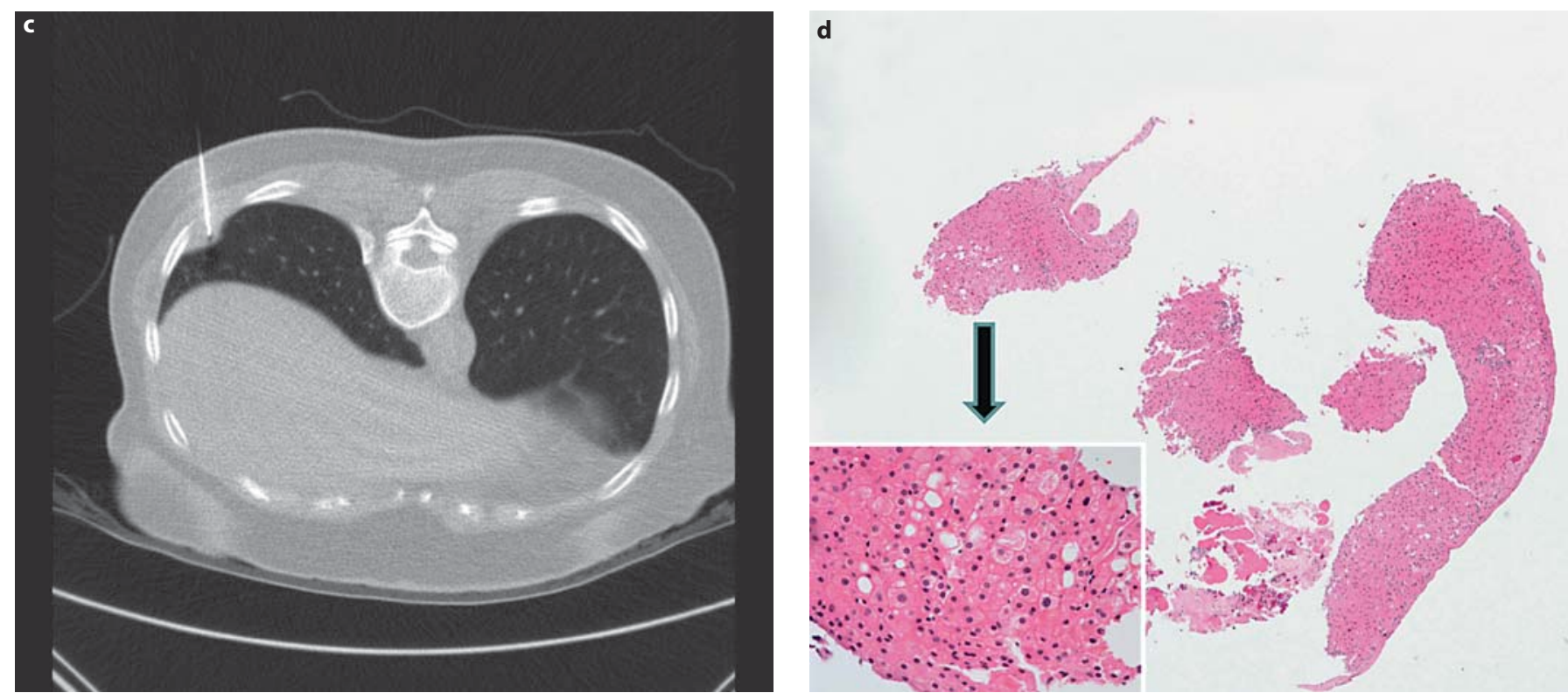

Fig. 1. c For diagnosis, transthoracic needle biopsy was conducted under CT guidance. d Final diagnosis revealed a normal hepatic tissue with fatty change. H\&E staining, $\times 40, \times 400$.

needle biopsy was conducted (fig. 1c). Tissue diagnosis revealed a normal hepatic tissue, suggesting an ectopic liver in the thoracic cavity (fig. 1d). The patient did not receive any further treatment and has remained stable without any evidence of complication.

Ectopic liver tissue is usually found in the abdomen, rarely involving the thoracic cavity. It is mostly congenital and asymptomatic, therefore incidentally found [1]. Although surgery is not always required, reported cases were almost always surgically resected due to misdiagno- sis [2]. Meticulous diagnostic workup demonstrated in this case may help to avoid unnecessary surgical operation, considering its modest clinical importance.

\section{Financial Disclosure and Conflicts of Interest}

None of the authors has a conflict of interest with regard to the study conduct or the data presentation of this study. This study was supported by a Korea University grant.

\section{References}

Wang Y, Junlin L, Zhang WG, Chen JH, He Y, Chen JM: Accessory lobe of right liver mimicking a pulmonary tumor in an adult male. Ann Thorac Surg 2010;89:e9-e10.
2 Rendina EA, Venuta F, Pescarmona EO, Ricci C: Intrathoracic lobe of the liver: case report and review of the literature. Eur J Cardiothorac Surg 1989;3:75-78. 